\section{A Comparison of a Gardening and Nutrition Program with a Standard Nutrition Program in an Out-of-school Setting}

\author{
Suzanne A. Poston ${ }^{1}$, Candice A. Shoemaker ${ }^{1}$, and \\ David A. Dzewaltowski²
}

ADDITIONAL INDEX WORDS. children's fruit and vegetable consumption, afterschool programs, children's nutrition education, gardening self-efficacy

\begin{abstract}
SUMmARY. After-school time is currently underutilized as a potential setting to promote healthy eating in children. Two programs, a standard nutrition program titled Professor Popcorn (PP) and a gardening and nutrition program using lessons from Junior Master Gardener: Health and Nutrition from the Garden (JMG), were compared to investigate their influence on nutrition knowledge, improving fruit and vegetable preference, and improving self-efficacy in gardening and eating fruit and vegetables in an out-of-school setting. Third through fifth graders participated in an after summer-school program $(n=11$ in $P P ; n=$ 7 in JMG), and fourth graders participated in JMG $(n=11)$ during the fall after school. Knowledge, preference, and self-efficacy measures were obtained at the beginning and end of the program. Neither program improved nutrition knowledge, nor were there any differences between the PP and JMG mean difference scores. The programs did not improve fruit and vegetable preference or fruit and vegetable consumption self-efficacy. There was, however, a change in gardening self-efficacy for the summer JMG group compared with that of the fall JMG group. Gardening self-efficacy of the summer JMG group increased $(P<0.10)$, whereas that of the fall JMG group decreased $(P<0.05)$. Further investigations should examine the activities of gardening occurring at different times throughout the growing season, and the role that seasons have on the outcomes due to a garden-enhanced nutrition program. In addition, researchers should examine the amount of classroom time vs. gardening time that is needed to make a gardenenhanced nutrition program more effective in an out-of-school learning setting.
\end{abstract}

I mproving fruit and vegetable consumption in children is an overwhelming challenge in the United States. Nutrition guidelines state that eating a minimum of five fruit and vegetables per day contributes to a healthier diet and helps prevent cancer and heart disease (Amer. Cancer Soc., 2004; Amer. Heart Assoc., 2004; USDA, 2004). In the 1989-91 Continuing Surveys of Food Intakes by Individuals (CSFII), fruit and veg-

${ }^{1}$ Graduate Student and Associate Professor, respectively, Department of Horticulture, Forestry and Recreation Resources, Kansas State University, 2021 Throckmorton Plant Sciences Center, Manhattan, KS 66506. To whom reprint requests should be addressed; cshoemak@ksu.edu

${ }^{2}$ Professor and Director, Community Health Institute, lA Natatorium, Kansas State University, Manhattan, KS 66506

Contribution no. 04-443-J of the Kansas Agricultural Experiment Station, Manhattan, Kans. This paper is a portion of a master's thesis submitted by S.A. Poston. The funding for this research was provided by the USDA Food Stamp Program through a contract awarded by the Kansas Department of Social and Rehabilitation Services. The authors thank Carol Fink for her assistance with the Summer 2003 program delivery. etable intakes for children ages 2-19 years were reported as being 1.3 and 2.6 servings/d, respectively (Muñoz et al., 1997). Muñoz et al. (1997) also reported that only $26 \%$ of children and adolescents met the food guide pyramid recommendations for fruit, and roughly $36 \%$ met the recommendations for vegetables during a consecutive 3-d period. Krebs-Smith et al. (1996) reported that the total daily fruit and vegetable intake for 6- to 11-year-old children is an average of 3.4 servings for boys and 3.5 servings for girls. Also, only one in five children consumed five or more servings of fruit and vegetables per day, and nearly onefourth of all vegetables consumed were reported as french fries (Krebs-Smith et al., 1996).

Due to the low fruit and vegetable consumption in children, nation-wide fruit and vegetable promotion programs have been developed to educate children and their families about the benefits of increasing fruit and vegetables in their diet (Heimendinger and Chapelsky, 1996; Reynolds, 1991; U.S. Department of Health and $\mathrm{Hu}-$ man Services, 2000). In addition to teaching nutrition knowledge of fruit and vegetables, programs have been designed to target an increase in fruit and vegetable consumption behavior (Levine et al., 2002; Perry et al., 1998, 2004; Reniscow et al., 1998).

Recent research based on social cognitive theory has shown that gardening can be an effective strategy to increase school children's knowledge and preferences for fruit and vegetables (Canaris, 1995; Cason, 1999; Lineberger and Zajicek, 2000; Morris and Zidenberg-Cherr, 2002; Morris et al., 2001, 2002). For example, DeMarco et al. (1999) found that $58.9 \%$ of 236 elementary school teachers surveyed stated that they used school gardening to teach subjects like health and nutrition. Gardening increased first grader's willingness to try new fruit and vegetables that they grew, and also showed a significant improvement in the intervention group's ability to visually identify the food groups (Morris et al., 2001). Morris and ZidenbergCherr (2002) showed that a gardening and nutrition program improved nutrition knowledge and preferences for some vegetables; the improved nutrition knowledge was even maintained at the 6 month follow-up. Lineberger and Zajicek (2000) reported that children preferred vegetables more after participating in a gardening and nutrition program.

School-based programs face great challenges for implementation due to the increasing focus in the U.S. on basic educational skills and test scores. Due to the time period that exists between parents' working hours and children's school hours, out-of-school programs offered in the summer and after school have been identified as one of the potentially important environments for youth development efforts (National Research Council and Institute of Medicine, 2002) and may be a particularly effective place for nutrition promotion programs. No previous studies have evaluated a program that incorporated gardening with nutrition lessons that was delivered in out-ofschool settings.

To evaluate nutrition program efforts, Baranowski and collegues have proposed that the theory-based processes of behavior change or mediators of a program's impact be 
identified and programs be designed to target the hypothesized mediators (Baranowski et al., 1997). The underlying rationale is that if a program is designed to influence behavior change processes, then it will ultimately be more effective in influencing nutrition behavior. Social cognitive theory has postulated that behavior change is mediated by children's expectations of confidence to perform the behavior (i.e., how confident they are in doing a particular behavior, which is referred to as self-efficacy) and children's expectations for the outcomes they will receive from that behavior (i.e., what children expect will happen as a result of doing a particular behavior, which is referred to as outcome expectations). A large body of literature has supported this hypothesis for numerous health behaviors (for a review see Bandura, 1997, 2004. The objective of this study was to evaluate the effectiveness of a garden-enhanced nutrition curriculum with respect to nutrition knowledge, fruit and vegetable preference, and self-efficacy for gardening and eating fruit and vegetables in a third through fifth grade children's out-of-school learning setting.

In this study, a gardening and nutrition education program was designed with an 8-lesson curriculum from the JMG program (Genzer et al., 2001), which targeted developing self-efficacy and preferences for fruit and vegetables. The curriculum's strategies included providing knowledge, skill development in gardening practice, modeling healthy eating and good gardening practices, and making fruit and vegetables available. At each lesson instructors provided information, skills, and modeled both good gardening practices and healthy eating behaviors. In addition, healthy snacks were provided at each lesson time. The omnibus hypothesis was that these strategies would increase students' gardening knowledge, and in turn, self-efficacy in gardening. An increase in these behavior change processes, then would affect the student's willingness to try those vegetables they grew, and in turn affect their self-efficacy for eating fruit and vegetables, as well as their preference for those fruit and vegetables. An illustration of this hypothesis can be found in Figure 1.

\section{Materials and methods}

Design and participants. This study was a quasi-experimental design with baseline and end-program measurements. To test the effectiveness of teaching nutrition to children, we compared eight lessons selected from the JMG curriculum with a standard nutrition education curriculum, Professor Popcorn. Professor Popcorn is an existing curriculum that is being taught to this cohort by USDA programs in Kansas.

Participants were recruited from a Boys and Girls Club. The target audience for this study were students in fourth grade because both curricula were appropriate for the third through fifth grade cohort, and the testing measurements are valid for the fourth grade (Domel et al., 1993, 1995, 1996). However, because enrollment of fourth graders was low, third through fifth grade students were recruited in the summer, and fourth grade students were recruited in the fall.

Data were collected at two intervals. In Summer 2003, both curricula were taught in succession, with seven participants in the JMG $\left(\mathrm{JMG}_{\mathrm{S}}\right)$ group and eleven participants in the PP group. In Fall 2003, researchers were able to teach another round of the JMG $\left(\mathrm{JMG}_{\mathrm{F}}\right)$ curriculum with 11 different participants. Thus, a total of 18 children received the JMG curriculum and 11 received the PP curriculum.

NUTRITION PROMOTION PROGRAMS. JMG group. This program focused on teaching nutrition through gardening, and was developed by Texas A\&M University Cooperative Extension. Eight lessons from the curriculum were chosen to provide a mixture of gardening and nutrition lessons (Table 1). Lessons from this curriculum have variable recommended lesson times ranging from 20 to $60 \mathrm{~min}$. Each lesson has stated objectives, subject information, discussion questions, and activities.

Professor Popcorn group. The PP curriculum was developed by Purdue

\section{Mediators}

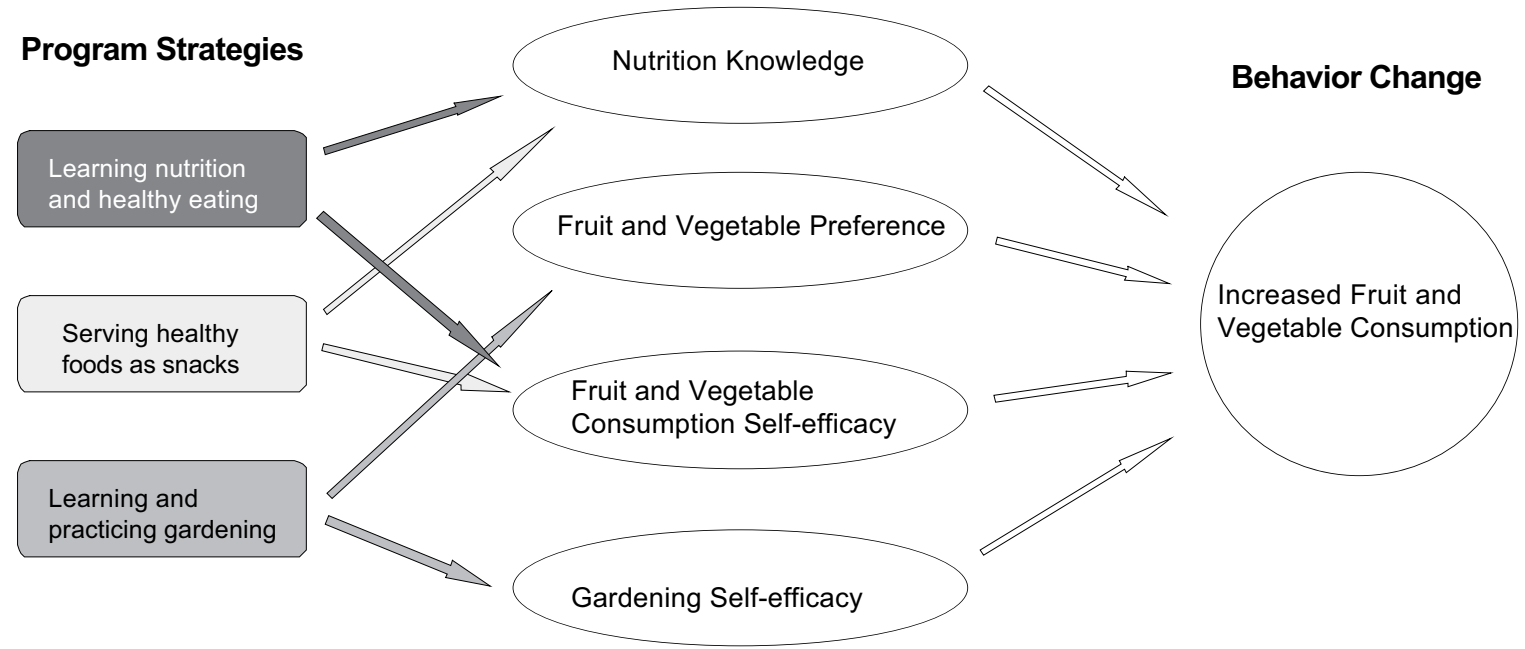

Fig. 1. Illustration of program strategies for an eight-lesson gardening and nutrition program and the strategies' potential effect on specific mediators of fruit and vegetable consumption. 
Table 1. Eight lessons selected from the Junior Master Gardener: Health and Nutrition from the Garden curriculum that reflected a balance of gardening and nutrition lessons. The eight lessons were used in a gardening and nutrition program, and were compared with a standard nutrition program for third to fifth grade children.

\begin{tabular}{ll}
\hline Lesson name & $\begin{array}{l}\text { Program } \\
\text { objective }\end{array}$ \\
\hline Plant Needs & Gardening \\
Rules 'n Tools & $\begin{array}{l}\text { Gardening } \\
\text { Make Your Pick }\end{array}$ \\
The Pyramid & Gardening \\
Taste Test & Nutrition \\
Fruit and Veggie Lab & Botanition \\
Apple Surprise & Nutrition \\
Fruit and Veggie Mania & Review \\
\hline
\end{tabular}

University Cooperative Extension, and focuses on teaching healthy eating according to the food guide pyramid, and safe food handling and storage practices. This curriculum has five lessons, which range in length from 30 to $60 \mathrm{~min}$. Nutrition concepts, sample recipes, and nutrition, food safety and physical activities are included in each lesson.

Program delivery. The study was designed to teach one lesson from the curriculum per week. Two researchers were present each week during program delivery. Each curriculum was taught by a different researcher, while the other researcher assisted. The JMG intervention was taught 8 weeks whereas the PP intervention was taught for 5 weeks. Each week, children were served a healthy snack, taught the lesson, and in the JMG groups, did gardening, for a total weekly meeting time of $90 \mathrm{~min}$. Estimated total gardening time per week was from 10 to $15 \mathrm{~min}$ for the JMG groups. The weekly lesson covered the material as given in the curricula.

Measures. Because self-efficacy and preferences are important mediators of fruit and vegetable consumption in children (Bandura, 1997, 2004; Reynolds et al., 1999), these elements, along with nutrition knowledge, were the variables that were measured in this study.

Nutrition knowledge was assessed by using a 10 -item test. Six items were multiple choice, and four were in true/ false format. The items were derived directly from the nutrition centered lessons of Junior Master Gardener: Health and Nutrition from the Garden (Genzer et al., 2001) and questions provided by Purdue University Extension and Texas A\&M University.

A 12-item list of common fruit and vegetables was used to measure fruit and vegetable preference (Cronbach's alpha $=0.654)$. This method was adapted from Domel et al. (1993). Students marked whether they liked each item a lot, liked a little, disliked, or did not know. Items that were liked a lot were given 2 points, liked a little were given 1 point, and disliked items received 0 points. Items that were marked, "don't know" were coded with a 9 and given 0 points. Scores were summed to produce a total fruit score (total possible $=8$ ) and a total vegetable score (total possible $=16$ ).

Self-efficacy items in this questionnaire were developed by the researchers, and were modeled following Bandura's (1997) recommendations and past work on children and health behavior (Domel et al., 1996; Ryan and Dzewaltowski, 2002). Two categories of self-efficacy were included in this questionnaire: gardening selfefficacy (Cronbach's alpha $=0.801$ ) and self-efficacy for eating fruit and vegetables $($ Cronbach's alpha $=0.431)$. Each category consisted of items that were context-specific according to that particular category of self-efficacy, for a total of nine items. For example, gardening self-efficacy contained five task-specific items related to gardening. Students marked how sure they were that they could do the specific task listed (e.g., plant a seed that will grow into a plant). The students responded on a three-item scale whether they were sure, somewhat sure, or not sure that they could do that particular task. Answers marked as sure were scored with 2 points, somewhat sure were scored with 1 point, and not sure were assigned 0 points. All five items in that self-efficacy category were then summed to produce a total gardening self-efficacy score; total possible scores were 10 and 8 for the gardening and fruit and vegetable consumption selfefficacy categories, respectively.

The questionnaire also contained a demographics section. Gender, race, home-life, age and previous gardening experience demographics questions were asked.

Data analysis. All data were analyzed with SPSS (version 11.5;
SPSS, Chicago) software by using nonparametric methods with Exact Tests. Exact Texts is a SPSS software addendum that calculates exact probability values for small and non-normally distributed data. Instrument reliability for each measure, except the nutrition knowledge scale, was calculated by using Cronbach's alpha coefficient. Cronbach's alpha is a useful coefficient for assessing internal consistency. In other words Cronbach's alpha indicates how well the items in a scale measure the same thing, in our case preference and self-efficacy. The nutrition knowledge scale tested a variety of nutrition concepts rather than offering many questions on one aspect of nutrition, so Cronbach's alpha test was not appropriate. Between group analyses were conducted using the Mann-Whitney and Kruskal-Wallis methods, and the within group analyses were conducted by using the Wilcoxon signed rank test for all measures except fruit and vegetable consumption selfefficacy. Due to the low Cronbach's alpha for this measure, only the means are reported.

\section{Results and discussion}

SumMary STATISTICS OF THE DEMOGRAPHIC DATA. JMG groups. JMG participants ranged from 8 to 11 years old. Ten students were 9 , four were 8 , three were 10 , and one student was 11 years old, and $50 \%$ of the students were male. Eleven students in the group were White, five were African American, and one student was Asian and one child's ethnicity was unknown. Fifty percent (nine) of the JMG participants lived with both parents, and about 17\% (three) lived with just their mother. The other six students had diverse answers when asked, "With whom do you live?"

PP group. The age range of the PP participants was from 7 to 11 years old; two students were 7 , four students were 8 , two students were 9 , and three students were 11 years old. Five of the participants in the PP group were boys. Seven of the students were White, two were African American, one was Asian, and one student was inconsistent in reporting his race. In response to the question of "With whom do you live?"; five students lived with their mother and father, three lived with just their mother, and the other three students gave diverse answers.

Nutrition KNOWLedGe.Baseline 
nutrition knowledge scores of the participants (Table 2) showed that students answered more than 50\% of the test questions correctly, which indicates that this sample already had high familiarity with the nutrition concepts that were to be taught in the program.

The baseline scores between groups were significantly different $(P$ $\leq 0.10$ ), therefore, the mean difference between the baseline and end-program score was analyzed. There were no differences between or within groups in this study (Table 2). Out-of-school programs that have targeted other academic areas have been successful with this audience (Schinke et al., 2000). Morris and Zidenberg-Cherr's (2002) study of a garden-enhanced nutrition program within the school day improved fourth-grade school children's knowledge of nutrition.

Preference. For fruit preference, there were no significant differences between or within groups at baseline or at end-program (data not shown). Overall, the participants preferred about $70 \%$ of the fruit listed in the preference list at baseline and endprogram. These results are similar to Baranowski et al. (1993), Domel et al. (1993), and Lineberger and Zajicek (2000). These researchers found that the mean preference scores for fruit were higher than those for vegetables at baseline and end-program, and found that students in focus groups reported liking many fruit but only one or no vegetables.

There were no significant differences in vegetable preference over the course of the program for any group (JMG groups were analyzed separately due to a significant difference in baseline scores) (Table 3). Overall, participants preferred about $50 \%$ of the vegetables listed at baseline and end-program. These results are inconsistent with current literature that indicate garden-enhanced nutrition programs increase students' vegetable preference (Lineberger and Zajicek, 2000; Morris and Zidenberg-Cherr, 2002). This literature does not provide a clear understanding of how these curricula were delivered. Small sample size, program length, and gardening time of our program may be factors that influenced our results.

Self-efficacy. Mean fruit and vegetable consumption self-efficacy scores for the JMG group were 6.33

Table 2. The mean difference in nutrition knowledge score ${ }^{z}$ of third to fifth grade students who participated in either a gardening and nutrition program or a standard nutrition program.

\begin{tabular}{lcccc}
\hline Group $^{y}(\mathbf{n})$ & Baseline $^{\mathrm{x}}$ & End-program & Mean difference & Significance \\
\hline $\operatorname{PP}(11)$ & 5.64 & 6.36 & 0.73 & NS \\
JMG $(18)$ & 7.11 & 7.61 & 0.50 & NS \\
Significance & $*$ & NS & NS & \\
\hline
\end{tabular}

${ }^{\mathrm{z}}$ Maximum possible score was 10 .

yPP = Professor Popcorn curriculum; JMG = Eight lessons from the Junior Master Gardener: Health and Nutrition from the Garden curriculum (summer and fall groups combined)

${ }^{x}$ Baseline scores between the two curricula groups were significantly different $(P=0.034)$, hence between group analysis used mean difference in scores.

Ns, ${ }^{*}$ Nonsignificant or significant at $P \leq 0.10$.

Table 3. Vegetable preference and gardening self-efficacy mean scores of third to fifth grade students who participated in either a gardening and nutrition program or a standard nutrition program.

\begin{tabular}{|c|c|c|c|c|c|c|}
\hline \multirow[b]{2}{*}{$\begin{array}{l}\text { Group }^{x} \\
(\mathbf{n})\end{array}$} & \multicolumn{3}{|c|}{ Vegetable preference $^{\mathrm{z}}$} & \multicolumn{3}{|c|}{ Gardening self-efficacy } \\
\hline & Baseline & $\begin{array}{c}\text { End- } \\
\text { program }\end{array}$ & Significance & Baseline & $\begin{array}{c}\text { End- } \\
\text { program }\end{array}$ & Significance \\
\hline $\mathrm{PP}(11)$ & 8.45 & 8.45 & NS & 7.27 & 7.36 & NS \\
\hline $\mathrm{JMG}_{\mathrm{S}}(7)$ & $8.45^{w}$ & 9.91 & NS & $6.00^{\mathrm{w}}$ & 7.86 & * \\
\hline $\mathrm{JMG}_{\mathrm{F}}(11)$ & $9.86^{\mathrm{w}}$ & 8.00 & NS & $8.64^{\mathrm{w}}$ & 7.00 & ** \\
\hline
\end{tabular}

${ }^{2}$ Maximum possible score was 16 .

'Maximum possible score was 10.

${ }^{x} \mathrm{PP}=$ Professor Popcorn curriculum; JMG = eight lessons from the Junior Master Gardener: Health and Nutrition from the Garden curriculum (summer and fall groups not combined).

wJMG scores for vegetable preference and gardening self-efficacy were analyzed separately due do a significant difference in their baseline scores, $P \leq 0.10$.

Ns, ${ }^{*}{ }^{* *}$ Nonsignificant or significant at $P \leq 0.10$ or 0.01

(maximum possible score was 8 ) at baseline and 5.56 at end-program, and the PP group had baseline and end-program scores of 5.82 and 5.91 respectively. These results are consistent with Domel et al. (1996), who stated that the students in their study reported being somewhere between "a little confident/sure" and "very confident/sure" that they could do the various tasks concerning eating more fruit and vegetables.

Over the course of the program, scores (maximum possible was 10 ) for the $\mathrm{JMG}_{\mathrm{S}}$ group for gardening self-efficacy increased $(P \leq 0.10)$, but scores of the $\mathrm{JMG}_{\mathrm{F}}$ group decreased $(P \leq$ 0.01 ) (Groups were not combined due to a significant difference in baseline score) (Table 3). Season and gardening method may have contributed to these differences. Also, the vegetables grown were different. In the summer, students planted cucumbers (Cucumissatious), sweet corn (Zea mays var. saccharata), eggplant (Solanum melongenavar. esculentum), peppers (Capsicum annuum var. annumm), squash (Cucurbita pepo var. melopepo), and watermelon (Citrullus lanatus); and harvested carrots (Daucuscarotavar. satipus), potatoes (Solanum tuberosum), radishes
(Raphanus sativus), and tomatoes (Lycopersicon lycopersicum) that were already established in the garden bed. The fall students grew broccoli (Brassica oleracea var. botrytis), cabbage ( $B$. oleracea var. capitata), green onion (Allium fistulosum), lettuce (Lactuca sativa), radishes, and spinach (Spinacia oleracea) in containers, and were able to harvest the lettuce and radishes during the program. To the best of our knowledge, no other study has measured self-efficacy in gardening with this age group.

\section{Conclusions}

Student in both groups (JMG and PP) did not improve in their nutrition knowledge. This research supports reported literature that children have a high preference for fruit and a moderate preference for vegetables. The JMG groups responded differently for gardening self-efficacy. Consequently, further research should examine the effect program time, gardening time, gardening method, and season have on the outcome(s) of a garden-enhanced nutrition program.

Study Limitations. Participants in this study were directly recruited, so a potential bias lies in the recruitment 
process. Since parents had to sign the student permission forms, parents who believed that their child needed to learn nutrition could have been more likely to register their children for this program. In addition, small sample size, and the inclusion of third grade children could have affected the analysis of the instrument, and the program analysis. Finally, attendance for the participants in this study was not consistent, nor complete.

\section{Literature cited}

American Cancer Society. 2004. Cancer prevention and early detection facts and figures 2004. 22 Sept. 2004. <http://www. cancer.org/docroot/STT/stt_0.asp/>.

American Heart Association. 2004. Food pyramid guidelines. 1 June 2004. < http:// www.deliciousdecisions.org/ $>$.

Bandura, A. 1997. Self-efficacy: The exercise of control. Freeman, New York.

Bandura, A. 2004. Health promotion by social cognitive means. Health Educ. Behavior 31(2):143-164.

Baranowski, T., L. Lin, D. Wetter, K. Resnicow, and M. Hearn. 1997. Theory as mediating variables: Why aren't community interventions working as desired? Annals Epidemiology 7(S7):S89-S95.

Baranowski, T., S. Domel, R. Gould, J. Baranowski, S. Leonard, F. Treiber, and R. Mullis. 1993. Increasing fruit and vegetable consumption among $4^{\text {th }}$ and $5^{\text {th }}$ grade students: Results from focus groups using reciprocal determinism. J. Nutr. Educ. 12(3):185-190.

Canaris, I. 1995. Growing foods for growing minds: Integrating gardening and nutrition education into the total curriculum. Children's Environ.12(2):264-270.

Cason, K.L. 1999. Children are "growing healthy" in South Carolina. J. Nutr. Educ. 31(4):235A.

DeMarco, L.W., D. Relf, and A. McDaniel. 1999. Integrating gardening into the elementary school curriculum. HortTechnology 9(2):276-281.

Domel, S.B., W.O. Thompson, H.C. Davis, T. Baranowski, S.B. Leonard, and J. Baranowski. 1996. Psychosocial predictors of fruit and vegetable consumption among elementary school children. Health Educ. Res. Theory Practice 11(3):299-308.
Domel, S.B., T. Baranowski, H.C. Davis, W.O. Thompson, S.B. Leonard, and J. Baranowski. 1995. A measure of outcome expectations for fruit and vegetable consumption among fourth and fifth grade children: Reliability and validity. Health Educ. Res. Theory Practice 10(1):65-72.

Domel, S., T. Baranowski, H. Davis, S. Leonard, P. Riley, and J. Baranowski. 1993. Measuring fruit and vegetable preferences among 4th and 5th grade students. Preventative Medicine 22:866-879.

Genzer S., R. Seagraves, J. Anding, L. Whittlesey, O. Aguilar, G. Graves, C. Klemmer, S. Koch, S. Lineberger, D. Reed, S. Robinson, C. Sebesta, P. V. Laanen, A. Wagner, C. Walton-Robinson, D.F. Welsh, D. Woodson, and J. Zajicek. 2001. Junior Master Gardener, Golden Ray Ser., Health and Nutrition from the Garden. Newman Publ., Bryan, Texas.

Heimendinger, J. and D. Chapelsky. 1996. The national 5-a-day for better health program. Adv. Expt. Medicine Biol. 401:199-206.

Krebs-Smith, S.M., D.A. Cook, A.F. Subar, L. Cleveland, J. Friday, and L.L. Kahle. 1996. Fruit and vegetable intakes of children and adolescents in the United States. Arch. Pediatric Adolescent Medicine 150:81-86.

Levine, E., C. Olander, C. Lefebvre, P. Cusick, L. Biesiadecki, and D. McGoldrick. 2002. The team nutrition pilot study: Lessons learned from implementing a comprehensive school-based intervention. J. Nutr. Educ. Behavior 34(2):109-116.

Lineberger, S.E. and J.M. Zajicek. 2000. School gardens: Can a hands-on teaching tool affect students' attitudes and behaviors regarding fruit and vegetables? HortTechnology 10(3):593-597.

Morris, J.L., K.L. Koumjian, M. Briggs, and S. Zidenberg-Cherr. 2002. Nutrition to grow on: A garden-enhanced nutrition education curriculum for upper-elementary schoolchildren. J. Nutr. Educ. Behavior 34(3):175-176.

Morris, J.L., A. Neustadter, and S. Zidenberg-Cherr. 2001. First-grade gardeners more likely to taste vegetables. California Agr. 55(1):43-46.

Morris, J.L. and S. Zidenberg-Cherr. 2002. Garden-enhanced nutrition curriculum improves fourth-grade school children's knowledge of nutrition and preferences for some vegetables. J. Amer. Dietetic Assn. 102(1):91-93.
Muñoz, K.A., S.M. Krebs-Smith, R. Ballard-Barbash, and L.E. Cleveland. 1997. Food intakes of US children and adolescents compared with recommendations. Pediatrics 100(3):323-329.

National Research Council and Institute of Medicine. 2002. Community programs to promote positive youth development. Natl. Academy Press, Washington, D.C.

Perry, C.L., D.B. Bishop, G. Taylor, D.M. Murray, R.W. Mays, B.S. Dudovitz, M. Smith, and M. Story. 1998. Changing fruit and vegetable consumption among children: the 5 -a-day power plus program in St. Paul, Minnesota. Amer. J. Public Health 88(4):603-609.

Perry, C.L., D.B. Bishop, G. Taylor, M. Davis, M. Story, C. Gray, S.C. Bishop, R.W. Mays, L.A. Lytle, and L. Harnack. 2004. A randomized school trial of environmental strategies to encourage fruit and vegetable consumption among children. Health Educ. Behavior 31(1):65-76.

Reniscow, K., M. Smith, T. Baranowski, J. Baranowski, R. Vaughan, and M. Davis. 1998.2-year tracking of children's fruit and vegetable intake. J. Amer. Dietetic Assn. 98(7):785-789.

Reynolds, K.D., A.W. Hinton, R.M. Shewchuk, and C.A. Hickey. 1999. Social cognitive model of fruit and vegetable consumption in elementary school children. J. Nutr. Educ. 31(1):23-29.

Reynolds, T. 1991.5-a-day for better health program is launched in Boston. J. Natl. Cancer Institute 83:1538-1539.

Ryan, G.J. and D.A. Dzewaltowski. 2002. Comparing the relationships between different types of self-efficacy and physical activity in youth. Health Educ. Behavior 29(4):491-504.

Schinke, S.P., K.C. Cole, and S.R. Poulin. 2000. Enhancing the educational achievement of at-risk youth. Prevention Sci. l(1):51-60.

U.S. Department of Agriculture. 2004. The food guide pyramid: A guide to daily food choices. I June 2004. <http://www.nal. usda.gov/fnic/Fpyr/pmap.htm/>.

U.S. Department of Health and Human Services. 2000. Healthy people 2010: Understanding and improving health. Dept. Health and Human Serv. Publ. No. (PHS) 017-001-00543-6. U.S. Govt. Printing Office, Washington, D.C. 